\title{
Cost Reduction Strategies Used by Elderly Patients With Chronic Obstructive Pulmonary Disease to Cope With a Generic-Only Pharmacy Benefit
}

\author{
MICHELE M. SPENCE, PhD; RITA HUI, PharmD, MS; and JAMES CHAN, PharmD, PhD
}

\begin{abstract}
BACKGROUND: Generic-only pharmacy benefits may present more of a burden to patients with chronic disease conditions such as chronic obstructive pulmonary disease (COPD), where generic drug therapy choices are more limited.

OBJECTIVE: To evaluate the strategies that elderly patients with COPD use to manage their out-of-pocket (OOP) prescription expenses in a generic-only pharmacy benefit compared with similar patients with a single-tier copayment or a 2-tier pharmacy benefit with coverage of brand formulary drugs.
\end{abstract}

METHODS: Surveys were mailed to a sample of 3,000 Kaiser Permanente (California) patients (aged $\geq 65$ years) who had a diagnosis for COPD and received at least 1 prescription for a COPD-related medication during 2003. The sample was stratified by type of pharmacy benefit: generic-only, single copayment tier, and 2 copayment tiers. The survey contained questions about strategies used to reduce 00P prescription expenses, such as stop taking a prescribed medication purchase prescriptions out of the country, or discuss 00P prescription expenses with a physician. The likelihood of using specific strategies to reduce 00P prescription expenses was modeled using logistic regression. Covariates included social support, quality of life, smoking status, socioeconomic status, total prescription costs, and demographics.

RESULTS: A total of 1,624 surveys were returned, for a $54 \%$ response rate. Results from logistic regressions indicate that COPD patients with a generic-only benefit are significantly more likely to report that they discussed their 00P costs with their physician (odds ratio $[\mathrm{OR}]=9.02 ; 95 \%$ confidence interval [Cl], 6.1513.22), purchased their medications from another country $(0 \mathrm{R}=6.70 ; 95 \% \mathrm{Cl}$, 3.17-14.16) and reduced spending on food and clothing $(0 \mathrm{R}=4.06 ; 95 \% \mathrm{Cl}$, 2.70-6.12). They are also more likely to report that they had taken less than the prescribed amount of a regular medication $(0 \mathrm{R}=1.70 ; 95 \% \mathrm{Cl}, 1.25-2.31)$ and that they stopped taking one or more of their regular medications $(0 \mathrm{R}=1.77 ; \mathrm{Cl}$, $1.27-2.47)$. Patients with low annual household incomes $(<\$ 25,000)$ were significantly more likely to discuss their $00 \mathrm{P}$ costs with their physician ( $\mathrm{OR}=1.47 ; 95 \%$ $\mathrm{Cl}, 1.08-2.00)$ and to reduce spending on food and clothing $(\mathrm{OR}=1.97 ; 95 \% \mathrm{Cl}$, $1.42-2.73)$ than those with higher incomes. Approximately $15 \%$ of COPD patients obtained drug samples from their physicians as a method to reduce 00P costs, and there was no difference among the 3 groups in the prevalence of this cost management strategy. Overall, patients in the generic-only pharmacy benefit used an average of 3 methods to reduce 00P pharmacy costs compared with approximately 1.5 cost reduction methods used by patients in single-tier and 2-tier copayment designs who had coverage of formulary brand as well as generic drugs.

CONCLUSION: Elderly patients with COPD and a generic-drug-only pharmacy benefit are more likely to report using a variety of strategies to reduce their $00 \mathrm{P}$ costs compared with similar patients with single-tier copayment or 2-tier copayment pharmacy benefits. The most common strategy was discussing 00P costs with their physician, and use of this strategy was inversely related to household income. There was no difference in the proportion of COPD patients among the 3 pharmacy benefit groups that used drug samples from their physicians as a means to reduce 00P costs.

KEYWORDS: Medicare, Prescription benefit, Patient cost sharing, Prescription copayment

J Manag Care Pharm. 2006;12(5):377-82

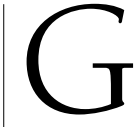
eneric drugs provide a safe and effective lower-cost alternative to the escalating costs of brand-name medications. The number of generic drug approvals increased from 186 during 1999 to more than 300 new approvals in 2005. ${ }^{1,2}$ An expanded range of generic equivalents, combined with continued growth in prescription costs and public demand for coverage of prescription drugs, had led an increasing number of Medicare Advantage plans to cover only generic medications in 2004 and 2005. During 2005, 39\% of Medicare Advantage beneficiaries were enrolled in plans that covered only generic drugs. ${ }^{3}$ Brand-name medications have been available, but, typically, they were paid $100 \%$ out of pocket (OOP) by the beneficiary.

As their OOP prescription expenses increased and their incomes remained fixed and limited, many Medicare beneficiaries with a generic-only benefit have had to make choices. They have been found to reduce their overall prescription drug use, especially brand-name medications. ${ }^{4}$ They may also rely on other strategies to reduce their OOP prescription expenses such as cutting back on living expenses, receiving financial assistance from family members, and purchasing necessary medications from other countries. Research has shown that among Medicare beneficiaries faced with increasing OOP costs under a capped benefit, the most frequently reported strategies for managing prescription expenses were to obtain samples from physicians, take less than prescribed amounts, use an over-the-counter product in place of a prescribed medication, and discontinue use of a regular medication. ${ }^{5,}$

Medically vulnerable beneficiaries who must rely on brandname medications may be adversely affected by a generic-only pharmacy benefit. Patients with chronic obstructive pulmonary disease (COPD) may be especially impacted because many of the medications used to treat COPD are available only as brand

\section{Authors}

MICHELE M. SPENCE, PhD, is a pharmacy outcomes project manager; RITA HUI, PharmD, MS, is a pharmacoeconomics and outcomes research pharmacist; JAMES CHAN, PharmD, PhD, is a pharmacy quality and outcomes coordinator, Drug Information Services, Kaiser Permanente, Downey, California.

AUTHOR CORRESPONDENCE: Michele M. Spence, PhD, Pharmacy Outcomes Project Manager, Drug Information Services, Kaiser Permanente, 12254 Bellflower Blvd., Downey, CA 90242. Tel: (562) 658-3528;

Fax: (562)658-3781; E-mail: michele.m.spence@kp.org

Copyright $\odot$ 2006, Academy of Managed Care Pharmacy. All rights reserved. 


\section{FIGURE 1 Sample Selection}

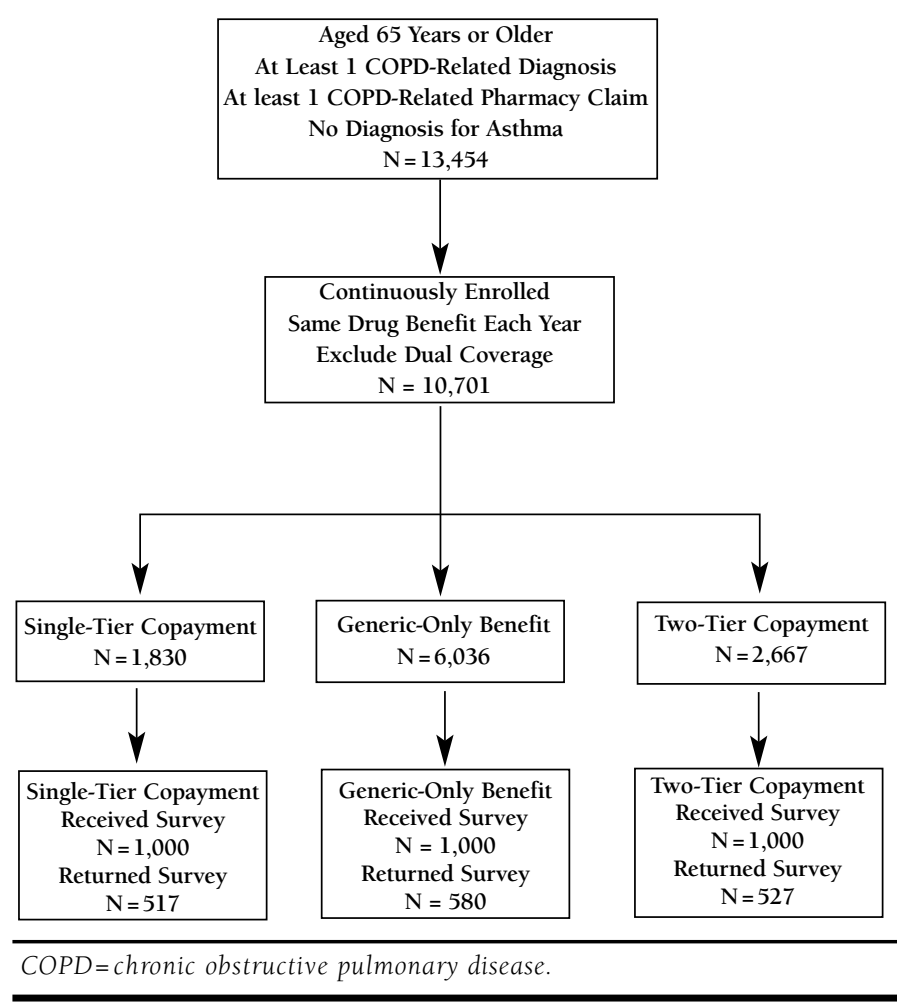

TABLE 1 Characteristics of Respondents, by Pharmacy Benefit Designs

\begin{tabular}{l|c|c|c|c}
\hline & $\begin{array}{c}\text { Single Tier } \\
(\mathrm{N}=517)\end{array}$ & $\begin{array}{c}\text { Two Tier } \\
(\mathrm{N}=580)\end{array}$ & $\begin{array}{c}\text { Generic Only } \\
(\mathrm{N}=527)\end{array}$ & $\begin{array}{c}\text { Total } \\
(\mathrm{N}=1,624)\end{array}$ \\
\hline $\begin{array}{l}\text { Age } \\
(\text { mean } \pm \text { SD) }\end{array}$ & $75.3(0.25)$ & $75.7(0.26)$ & $75.1(0.28)$ & $75.4(0.15)$ \\
\hline Female & $231(45 \%)$ & $284(49 \%)$ & $277(53 \%)$ & $793(49 \%)$ \\
\hline White & $433(87 \%)$ & $484(88 \%)$ & $467(92 \%)$ & $1,384(89 \%)$ \\
\hline $\begin{array}{l}\text { Low income } \\
(<\$ 25,000)\end{array}$ & $161(36 \%)$ & $176(36 \%)$ & $292(60 \%) *$ & $629(44 \%)$ \\
\hline $\begin{array}{l}\text { Low education } \\
(<\text { high school) }\end{array}$ & $59(12 \%)$ & $66(12 \%)$ & $85(17 \%)$ & $210(14 \%)$ \\
\hline $\begin{array}{l}\text { Social support } \\
\text { (mean } \pm \text { SD) }\end{array}$ & $58.33(1.60)$ & $57.92(1.51)$ & $55.47(1.55)$ & $57.25(0.89)$ \\
\hline $\begin{array}{l}\text { Current } \\
\text { smoking }\end{array}$ & $78(16 \%)$ & $81(15 \%)$ & $95(19 \%)$ & $254(17 \%)$ \\
\hline Past smoking & $414(89 \%)$ & $437(85 \%)$ & $396(86 \%)$ & $1,247(87 \%)$ \\
\hline Poor health & $102(20 \%)$ & $81(14 \%)$ & $102(20 \%)$ & $285(18 \%)$ \\
\hline $\begin{array}{l}\text { AQ20 } \\
\text { (mean } \pm \text { SD) }\end{array}$ & $8.52(0.22)$ & $8.59(0.21)$ & $8.98(0.23)$ & $8.70(0.13)$ \\
\hline
\end{tabular}

$* P<0.01$, chi-square statistical test.

AQ20=Airways Questionnaire 20 products (ipratropium, tiotropium, or albuterol-ipratropium). In addition, the prices of COPD-related medications have increased: brand-name respiratory inhalers incurred manufacturer price increases 3 times the rate of general inflation during the first 6 months of 2005. ${ }^{7}$ Medicare expenses for patients with COPD are nearly 2.5 times that of the expenditures for all other patients. ${ }^{8}$ Medicare beneficiaries with COPD and limited drug coverage are therefore faced with difficult decisions as they attempt to budget their OOP prescription expenses. In this study, we sought to evaluate the strategies that elderly patients with COPD who have a generic-only pharmacy benefit use to manage their OOP prescription expenses compared with similar patients with a single-tier or a 2-tier copayment pharmacy benefit.

\section{Methods}

This study was conducted at Kaiser Permanente (KP), California, a nonprofit, group-model health maintenance organization providing comprehensive health care to approximately 6 million members. On January 1, 2004, approximately 350,000 Medicare members in the Kaiser Permanente Senior Advantage (KPSA) individual plan were transferred to a generic-only pharmacy benefit. Under this new benefit, a majority of brand-name drugs were not covered. Members could purchase brand drugs at the discounted member price. A few select brand drugs continued to be covered at a $\$ 30$ brand copayment, such as brand drugs (e.g., antineoplastic agents and immunosuppresants) used to treat life-threatening conditions. For generic drugs, KPSA members had unlimited coverage with a $\$ 10$ copayment per prescription. Approximately 380,000 additional KP members aged 65 years and older had pharmacy benefits with coverage of both generic and formulary brand drugs in either a single-tier copayment (e.g., $\$ 5$ for either brand or generic) or 2-tier copayment (e.g., $\$ 5$ generic or $\$ 15$ formulary brand).

A self-administered survey was mailed in early December 2004 to 3,000 KP members who met the following criteria: aged 65 years or older, a diagnosis for COPD during 2003 (International Classification of Diseases, Ninth Revision, Clinical Modification [ICD-9-CM] codes 490, 491, 492.0, 492.8 , 496, or 506.4), no diagnosis for asthma (ICD-9-CM code 493), filled at least 1 prescription for a COPD-related medication during 2003 (ipratropium, tiotropium, or albuterol-ipratropium), and was continuously enrolled in KP from January 2003 through the time of survey mailing, with the same drug benefit each year. Members who had dual coverage (for example, coverage under both their own and their spouse's health plans) were excluded from the analysis. The institutional review boards of both the Northern and Southern California Regions of KP approved this study.

The sample was stratified by 3 levels of pharmacy benefits (1 study group and 2 comparison groups), with 1,000 patients in each group. We estimated that a sample size of 400 responders 
(40\% response) would be needed for each level at the $95 \%$ level of confidence and for confidence intervals of $\pm 5 \%$ for variables expressed as proportions. ${ }^{9}$ The study group consisted of patients with a generic-only benefit in which they paid member (discount) price for brand medications and a $\$ 10$ copayment for each generic prescription. The 2 comparison groups included patients with a single-tier benefit who paid a single, flat copayment for all medications and those with a 2-tier benefit. Under the single-tier benefit, copayments ranged from $\$ 0$ to $\$ 10$. The 2-tier benefit patients paid a $\$ 5$ or $\$ 10$ copayment for generics and a $\$ 10, \$ 15$, or $\$ 20$ copay for brand medications. The sampling procedure is described in Figure 1.

The survey instrument contained questions on strategies that patients use to manage their OOP expenses based, in part, on a survey developed by Cox et al., ${ }^{5,6}$ Patients were asked to think back since January 2004 and to indicate if they had engaged in any strategies to reduce their OOP expenses. The list included strategies such as "took less than the prescribed amount of one or more of your medications," "purchased one or more of your medications from another country," and "discussed your out-of-pocket prescription expenses with your doctor." We also included the short version of the RAND Medical Outcomes Study (MOS) Social Support (SSUP) scale to adjust for the amount of social support available to the patient. ${ }^{10}$ This validated, 4-question scale asked if there was someone to help if the respondent was confined to bed, needed to go to the doctor, or needed help with meals and daily chores. Scores range from 0 to 100, with higher scores indicating a need for greater social support. To control for variations in health-related quality of life, we added the Airways Questionnaire 20 (AQ20). ${ }^{11,12}$ This is a 20-question scale validated for use among patients with asthma and/or COPD. Scores range from 0 to 20; higher scores indicate a poorer quality of life. Finally, there were questions on health status, smoking history, ethnicity, marital status, education, and annual household income.

\section{Analysis}

Descriptive statistics included differences in frequencies and percentages using $t$ tests and chi-square distributions. Multivariate analysis was based on a logistic regression predicting the likelihood of participating in any one strategy. The main independent variable was drug benefit level: generic-only, 2-tier, or single-tier benefit. Covariates included AQ20 score, social support, self-reported health status, age, gender, smoking status, marital status, education, ethnicity, income, and total prescription costs during 2004. SAS statistical software version 8 was used for data analysis.

\section{Results}

A total of 1,624 surveys were returned, for a 54\% response rate. There was a slightly higher response rate among the 2-tier group (58\%) than the generic-only (53\%) or the single-tier

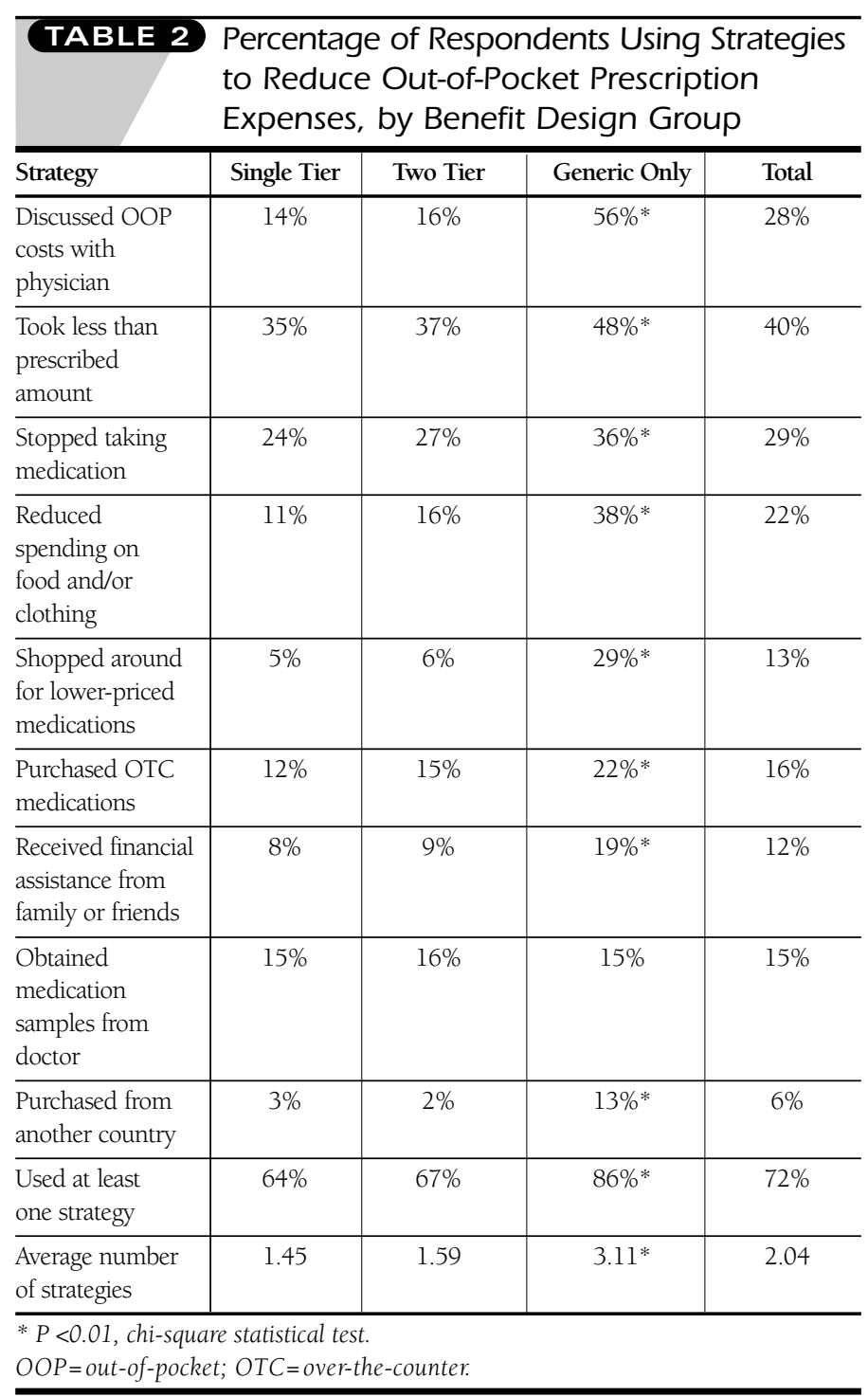

group (52\%). We checked for nonresponse bias by comparing the sampling frame and respondents on age and gender since these variables were available for all patients in the study. The gender and age distribution was not significantly different between respondents and the sampling frame $\left(\chi^{2}=1.71, d f=1\right.$; and $t=1.11, d f=2,858$, respectively).

As shown in Table 1, demographic characteristics did not differ significantly between the 3 benefit groups. The only exception was income: $60 \%$ of the generic-only group reported having low annual household incomes $(<\$ 25,000)$ compared with $36 \%$ in the other 2 groups. The average age was 75 years. As expected, a majority of the respondents (87\%) were ex-smokers. Approximately $17 \%$ of all respondents were still smoking as of the survey date, and $18 \%$ of all respondents described their health as poor. 


\section{TABLE 3 Likelihood of Participating in Strategies to Reduce Out-of-Pocket Prescription Expenses Among COPD Patients With a Generic-Only Pharmacy Benefit}

\begin{tabular}{|c|c|c|}
\hline Strategy & Odds Ratio & $95 \%$ CI \\
\hline Discussed OOP costs with physician & $9.02 *$ & $6.15-13.22$ \\
\hline Purchased from another country & $6.70^{*}$ & $3.17-14.16$ \\
\hline Reduced spending on food, clothing & $4.06^{*}$ & $2.70-6.12$ \\
\hline Took less than prescribed amount & $1.70^{*}$ & $1.25-2.31$ \\
\hline Stopped taking medication & $1.77^{*}$ & $1.27-2.47$ \\
\hline Shopped around & $1.53 *$ & $0.82-2.87$ \\
\hline \multicolumn{3}{|c|}{$\begin{array}{l}\text { Note: Adjusted by age, gender, marital status, education, income, ethnicity, } \\
\text { health status, smoking status, social support, AQ20, score and total prescription } \\
\text { costs. Comparison group is composed of patients with a single-tier copayment } \\
\text { benefit. } \\
* P<0.001 \text {, chi-square statistical test. } \\
\text { AQ20=Airways Questionnaire } 20 ; C I=\text { confidence interval; COPD=chronic } \\
\text { obstructive pulmonary disease; OOP=out of pocket. }\end{array}$} \\
\hline
\end{tabular}

Table 2 shows the percentage of respondents reporting specific strategies used to reduce their OOP prescription drug expenses. In the majority of cases, the generic-only group was significantly more likely to report using a strategy. Fifty-six percent of respondents in the generic-only group reported discussing their OOP costs with their physician compared with $14 \%$ in the single-tier and $16 \%$ in the 2-tier group. The genericonly group was more likely to reduce their prescription utilization: $48 \%$ reported taking less than the prescribed amount compared with $35 \%$ in the single-tier and $37 \%$ in the 2 -tier group, and $36 \%$ reported that they stopped taking a regularly prescribed medication compared with $24 \%$ in the single-tier and $27 \%$ in the 2-tier group. They were also more likely to reduce spending on food and clothing (38\%), shop around for lower-priced medications (29\%), purchase some medications over-thecounter $(22 \%)$, and receive financial assistance from family or friends (19\%). Thirteen percent of them reported purchasing their medications from another country compared with 3\% in the single-tier group and 2\% in the 2-tier group. Obtaining medication samples from a physician was the only strategy in which there were no significant differences; approximately 15\% of our sample reported using this strategy. Eighty-six percent of the generic-only group reported using at least 1 strategy and, on average, they used 3.11 strategies to reduce their OOP prescription expenses.

The likelihood of participating in strategies to reduce OOP prescription expenses among COPD patients with a genericonly benefit is presented in Table 3. After controlling for relevant covariates, those with a generic-only benefit were 9 times more likely to discuss their OOP costs with their physician than those patients with a single-tier benefit (odds ratio [OR] =
9.02; 95\% confidence interval [CI], 6.15-13.22). They were almost 7 times more likely to purchase medications from another country $(\mathrm{OR}=6.70 ; 95 \% \mathrm{CI}, 3.17-14.16)$ and 4 times more likely to reduce their spending on food or clothing $(\mathrm{OR}=4.06$; 95\% CI, 2.70-6.12). They were also significantly more likely to take less than the prescribed amount, stop taking a regularly prescribed medication, and shop around for better prices on prescription drugs. Odds ratios for the 2-tier group compared with the single-tier group (not shown) did not reach statistical significance.

Patients with low annual household incomes $(<\$ 25,000)$ were significantly more likely to discuss their OOP costs with their physician $(\mathrm{OR}=1.47 ; 95 \% \mathrm{CI}, 1.08-2.00)$ and to reduce spending on food and clothing ( $\mathrm{OR}=1.97 ; 95 \% \mathrm{CI}, 1.42-2.73$ ) than those with higher incomes. Income did not have a significant effect in any of the other strategies reported in Table 3. Because the generic-only group was significantly more likely to report low annual household incomes, a subanalysis was conducted to determine if low income, combined with a generic-only benefit, was a major factor in patient's behavior to reduce OOP costs. We stratified the strategies by income and found that in each income level, patients with a generic-only benefit continued to be more likely to engage in strategies to reduce costs. We also included income and benefit group as a multiplicative term in the regression models, but this did not reach statistical significance.

\section{Discussion}

This study provides a unique perspective on the impact of prescription drug cost sharing on a population with a chronic disease within an integrated health care system. Our findings showed that when brand drugs are not covered in the pharmacy benefit, elderly patients with COPD are using a variety of different strategies to adapt. The most common strategy was to discuss their OOP prescription costs with their physician. Previous research has shown that while most patients report a desire to talk with their physician about their OOP costs, only those who feel burdened by their costs actually do so. ${ }^{13}$ These discussions are potentially beneficial to patients who have to bear the full cost of some or all of their necessary medications. Cost-related conversations may reduce nonadherence and may help physicians ensure that patients use the most cost-effective medicines possible.

Thirteen percent of the generic-only group reported purchasing their medications from another country. This is higher than the 3\% of Medicare beneficiaries with high medication costs and a drug cap reported in a previous study. ${ }^{14}$ We do not know exactly what kinds of medications the respondents in our study are purchasing out of country. One patient wrote that "I purchased all inhalers out of country at great savings." Some patients have also received financial assistance from family and friends and have reduced spending in other areas to pay for their medications. While patients seem to be prioritizing and 


\section{Cost Reduction Strategies Used by Elderly Patients With Chronic Obstructive Pulmonary Disease to Cope With a Generic-Only Pharmacy Benefit}

leaning on others for help, it is not known whether they are reducing spending on food and other necessities to the extent that they are jeopardizing their health. This is particularly relevant to the generic-only group because $60 \%$ of them reported a household income of less than $\$ 25,000$ per year. Finally, $15 \%$ of our sample reported receiving medication samples from a physician; however, this finding was not significantly different between the 3 benefit groups. A previous study reported a much higher percentage-45\%-among their sample of Medicare beneficiaries. ${ }^{6}$ This difference is most likely due to KP's policy, which discourages the use of drug samples, driven by concerns about patient safety and unnecessary prescribing of samples for high-cost brand medications for which there are often lower-cost alternatives.

Patients with low incomes were more likely to talk to their physician and to reduce spending on food and clothing. However, we found that income was not a major factor for those with a generic-only benefit even though a majority of them had low annual household incomes. Regardless of income, those with a generic-only benefit were more likely to engage in costreduction strategies than those with other pharmacy benefits. Confronted with an abrupt increase in their medication costs, they found ways to reduce their OOP expenses across all income levels. Some strategies, such as purchasing from out-ofcountry via the Internet, may be more accessible to those with more financial resources.

Patients with a generic-only benefit are also engaging in behaviors that may produce adverse consequences for their health. They are almost twice as likely to take less than the prescribed amount and to stop taking a regularly prescribed medication. Important questions remain, such as: Are they discontinuing essential or discretionary medications? What are the effects on hospitalizations and emergency services? Analysis of actual data from administrative databases could provide answers and contribute to the growing body of research linking patient cost sharing to health outcomes. A study is under way to address these issues.

Pharmacist-directed programs, such as the medication therapy management programs (MTMPs) mandated under the new Medicare Part D, have the potential to help elderly patients with chronic diseases decrease their OOP drug expenses while maintaining appropriate drug therapy. Loss of brand-drug coverage could still be an issue for patients who reach the "doughnut hole," a coverage gap when their annual drug spending hits $\$ 2,250$, and cost sharing will continue to have effects as patients navigate premiums, deductibles, and copayments. The Pharmacist Review to Increase Cost Effectiveness (PRICE) Clinic is one example of such a program and has demonstrated a $68 \%$ decrease in OOP expenses, from $\$ 185$ to $\$ 60$ per patient per month. ${ }^{15}$ Forty-one percent of patients in the PRICE Clinic study reported that they had discontinued or would soon discontinue drugs because of cost; among these patients, $87 \%$ were able to continue or resume the drug as a result of PRICE Clinic interventions. In addition to generic substitution and therapeutic interchange, PRICE Clinic pharmacists conducted a variety of interventions, including patient assistance programs, mail-order services, manufacturer coupons, and tablet splitting. Such interventions could complement the appropriate strategies and avert potentially harmful behaviors taken by patients, especially those with low incomes and multiple chronic diseases, as they attempt to reduce their OOP prescription expenses.

\section{Limitations}

Our study has a number of limitations. First, the findings are based on self-reported surveys and may be subject to recall bias and socially desirable response bias. Second, these survey results represent the strategies and opinions of only about one half of the survey sample. Third, we surveyed patients within a single health care delivery system in California, and these results may not be generalizable to other health care settings. Fourth, we did not control for relevant clinical variables in the COPD population such as pulmonary function tests (e.g., forced expiratory volume in 1 second or forced vital capacity). We also did not control for comorbidities or the number of total prescription drugs for the patient. Also, patients with COPD only may differ in their responses compared with COPD patients with multiple diseases. However, we did control for related variables such as quality of life (AQ20), self-reported health status, and total prescription costs, which are likely to provide valid estimates of COPD patients' health condition.

\section{Conclusion}

Elderly patients with COPD who have a generic-only pharmacy benefit are more likely to report using a larger number of strategies to reduce their OOP expenses compared with similar patients who have coverage of brand formulary as well as generic drugs in either a single-tier or 2-tier copayment benefit. The most common cost reduction strategy was discussing their OOP expenses with their physician. They were also more likely to report taking less than the prescribed amount and that they stopped taking one or more of their regular medications. The proportion of patients in each of the 3 study groups that reported using physician drug samples to help reduce OOP cost was similar, about $15 \%$ in each group.

With the advent of Medicare Part D, most Medicare beneficiaries now have coverage for brand medications, at least until they reach the coverage gap. However, the effects of cost sharing will continue to be important as Medicare beneficiaries face a wide variety of premiums, deductibles, gaps in coverage, and copayment amounts.

\section{DISCLOSURES}

No outside funding supported this study research; it was funded internally by Kaiser Permanente (California). Authors Michele M. Spence, Rita Hui, and James Chan are employed by Kaiser Permanente (California). The authors disclose 


\section{Cost Reduction Strategies Used by Elderly Patients With Chronic Obstructive Pulmonary Disease to Cope With a Generic-Only Pharmacy Benefit}

no potential bias or conflict of interest relating to this article. Spence served as principal author of the study. Study concept and design were contributed by Spence with substantial input from Hui and Chan. Data collection was the work of Spence and Hui; data interpretation was primarily the work of Spence, with substantial contributions from Hui and Chan. Writing of the manuscript was the work of Spence, with input from the coauthors; its revision was primarily the work of Spence, with substantial contributions from the coauthors.

\section{REFERENCES}

1. U.S. Food and Drug Administration, Center for Drug Evaluation and Research. CDER 2004 Report to the nation: improving public health through human drugs. Available at: http://www.fda.gov/cder/reports/rtn/2004/ rtn2004.htm. Accessed May 22, 2006.

2. Food and Drug Administration. Generic drug approvals. Available at: http://www.fda.gov/cder/ogd/approvals/default.htm. Accessed May 22, 2006.

3. Kaiser Family Foundation. Medicare Advantage fact sheet. Available at: http://www.kff.org/medicare/upload/Medicare-Advantage-April-2005-FactSheet.pdf. Accessed May 22, 2006.

4. Christian-Herman J, Emons M, George D. Effects of generic-only drug coverage in a Medicare HMO [Web exclusive]. Health Aff. 2004;W4:455-68.

5. Cox ER, Jernigan C, Coons SJ, et al. Medicare beneficiaries' management of capped prescription benefits. Med Care. 2001;39(3):296-301.

6. Cox ER, Henderson RR. Prescription use behavior among Medicare beneficiaries with capped pharmacy benefits. J Manag Care Pharm. 2002;8(5):360-64.
7. AARP Public Policy Institute. Trends in manufacturer prices of brand name prescription drugs used by older Americans—second quarter 2005 update. Available at: http://assets.aarp.org/rgcenter/health/dd128_drugprices.pdf. Accessed May 22, 2006

8. National Heart, Lung, and Blood Institute. Chronic Obstructive Pulmonary Disease Fact Sheet. NIH Publication No. 03-5229; March 2003.

9. Rea LM, Parker RA. Designing and Conducting Survey Research: A Comprehensive Guide. San Francisco, CA: Jossey-Bass; 1992.

10. Sherbourne CD, Stewart AL. The MOS social support survey. Soc Sci Med. 1991;32:705-14.

11. Barley EA, Quirk FH, Jones PW. Asthma health status measurement in clinical practice: validity of a new short and simple instrument. Resp Med. 1998;92:1207-14.

12. Hajiro T, Nishimura K, Jones PW, et al. A novel, short, and simple questionnaire to measure health-related quality of life in patients with chronic obstructive pulmonary disease. Am J Resp Crit Care Med. 1999;150:1874-78.

13. Alexander GC, Casalino LP, Meltzer DO. Patient-physician communication about out-of-pocket costs. JAMA. 2003;290(7):953-958.

14. Tseng CW, Brook RH, Keeler E, et al. Cost-lowering strategies used by Medicare beneficiaries who exceed drug benefit caps and have a gap in drug coverage. JAMA. 2004;292(8):952-960.

15. Stebbins, MR, Kaufman, DJ, Lipton HL. The PRICE clinic for low-income elderly: a managed care model for implementing pharmacist-directed services. J Manag Care Pharm. 2005;11(4):333-41. 